\title{
Experimental Study and Finite Element Modelling of Reinforced Concrete Column Having An Opening
}

\author{
Suliman khan ${ }^{\mathrm{a}}$,Muneer Ahmed \\ a.Department of civil Engineering, \\ University of Engineering and Technology Taxila,Pakistan
}

\begin{abstract}
This study deals with the finite element modelling of reinforced concrete beam and column using ANSYS. The study covers a comprehensive introduction to ANSYS, such that any beginner can learn the useful and effective use of the ANSYS in order to model and analyze any type of structure like beam and column. ANSYS is a very handy and effective tool in modelling and analysis of various structural element based on finite element modelling. A detailed study of the work includes the modelling of beam and column with specific cross sections and reinforcement details. Further the column with a lateral hole at the center is evaluated in terms of cracking response around the hole. The experimental work is carried out in the concrete laboratory of civil engineering department UET Taxila. The results of that experimental work is then compared eventually with the results that's were obtained by analysis through ANSYS. As a summary of the work the results were compared in terms of the stress, strain and cracking around the hole. It is concluded that the response of the column around the hole/opening in terms of cracking pattern in both elastic and post elastic stages was much more comparable with that of experimental work.
\end{abstract}

Keywords: Finite element modelling, ANSYS, Column, Lateral hole, Stress, strain, Elastic, post elastic, cracking pattern.

DOI: $10.7176 /$ IEL/9-1-03

\section{Introduction}

For providing pipes for utility services, holes are required in structural members. Usually these holes are provided in beams and slabs as columns are critical members of a structural system and their failure results in partial or complete collapse of building. Limiting holes to only beams and slabs, results in complex network especially in multistory buildings. If holes (transverse) are provided in column by carefully taking in account the effect of stress distribution and reduction in load carrying capacity then it will result in more organized and economical network. Therefore this study is aimed at discussing alternate solutions using which hole in column can be provided without compromising on its original strength. The finite element method has thus become a powerful computational tool, which allows complex analyses of the nonlinear response of RC structures to be carried out in a routine fashion. With the help of this method the importance and interaction of different nonlinear effects on the response of RC structures can be studied analytically. A follow-up study will address the response of these structures under real time loading by Finite element modelling method using the most reliable tool i.e. ANSYS 17.0.

A brief review of previous studies on the application of the finite element method to the analysis of reinforced concrete structures is presented is this section.

In the earliest publication by Ngo and Scordelis (1967) on the application of the finite element method/modelling of RC structures, simple beams were analyzed by meshing it into triangular elements of constant strain and a special bond link element was used to connect the steel to the concrete. Also described the bond-slip effect while modelling RCC structure. A linear elastic analysis was performed on beams with predefined crack patterns to determine principal stresses in concrete, stresses in steel reinforcement and bond stresses.For the analysis of RC beams with material and geometric nonlinearities Rajagopal (1976) developed a layered rectangular plate element with axial and bending stiffness in which concrete was treated as an orthotropic material. RC beam and slab problems have also been treated by many other investigators (Lin and Scordelis 1975; Bashur and Darwin 1978; Rots et al. 1985; Barzegar and Schnobrich 1986; Adeghe and Collins 1986; Bergmann and Pantazopoulou 1988; Cervenka et al. 1990; Kwak 1990) using similar methods.The behavior of RC columns with longitudinal hole was studied using three-dimensional non-linear finite element method and the finite element modeling of the columns predict much higher strength for the columns than experimental result ( Basravi 2010).Study conducted by (Qais Majeed 2012) in which experimental and nonlinear finite element analysis of creating square openings in existing RC beams and strengthening with CFRP laminate was carried. The beams were modeled using a FEM packaged (ANSYS 11).The results indicate that the strengthened beam recorded the highest failure load and its mode of failure was ductile. The numerical results seemed to be able to predict the behavior of the beams.The behavior of reinforced concrete columns with holes under axial load is researched to help designers and structural code officials (Ehab M. Lotfy 2013) and the experimental results were compared with finite element model using ANSYS. 


\section{A).Experimental method}

In this Phase of the research work that is experimental program of the column as described has been discussed. Geometrical and material properties of columns with casting procedure along with test setup and testing procedure has been described in this phase.

In this section geometry and properties of columns which were tested have been summarized. A column specimen was square in shape of size $203 \mathrm{~mm}$ x $203 \mathrm{~mm}$, having a length of 1 meter. $51 \mathrm{~mm}$ diameter transverse hole was left in column while concreting exc. 4 bars of \#13 were used as longitudinal reinforcement.Column geometry and reinforcement detail are tabulated below.

Table\#01.

\begin{tabular}{|l|l|l|l|l|l|l|}
\hline $\begin{array}{l}\text { Concrete } \\
\text { Strength } \\
(\mathbf{M P a})\end{array}$ & $\begin{array}{l}\text { Steel } \\
\text { Strength, } \\
\text { Fy } \\
(\mathbf{M P a})\end{array}$ & $\begin{array}{l}\text { Column } \\
\text { size } \\
\mathbf{( m m )}\end{array}$ & $\begin{array}{l}\text { Column } \\
\text { length } \\
\mathbf{( m )}\end{array}$ & $\begin{array}{l}\text { Hole diameter } \\
(\mathbf{m m})\end{array}$ & $\begin{array}{l}\text { Longitudinal } \\
\text { reinforcement }\end{array}$ & $\begin{array}{l}\text { Transverse } \\
\text { reinforcement }\end{array}$ \\
\hline 28 & 414 & $\begin{array}{l}203 \times 203 \\
(8 ” \times 8 ")\end{array}$ & 1 & 51 & $\begin{array}{l}4-\# 13 \text { bars } \\
(4 \# 4 \text { bars })\end{array}$ & $\begin{array}{l}\# 10 @ 203 \mathrm{~mm} \mathrm{c} / \mathrm{c} \\
(\# 3 @ 8 " \mathrm{c} / \mathrm{c})\end{array}$ \\
\hline
\end{tabular}

\section{Material Properties}

Reinforcement bars and concrete used for casting of column specimens had the properties as described in given section.

\section{Reinforcement Bars}

Reinforcement bars used for column were deformed steel bars. For longitudinal bars \#13 bars of Grade 420 steel were used. Whereas for transverse bars \#10 bars of Grade 300 steel was used. Reinforcement bars conforming to ASTM A 615M were used. The Yield strengths of longitudinal and transverse reinforcement were approximately $420 \mathrm{MPa}$ and $280 \mathrm{MPa}$ respectively.

\section{Concrete}

For concrete, normal weight aggregates having maximum size of $1 / 2$ " were used. Cement used was Ordinary Portland Cement. Concrete mix design ratio of 1:2:4 was used for columns. Water to cement ratio was 0.5 . Concrete strength was determined by casting concrete cylinders 6" diameter and 12" length and testing under compression testing machine as per ASTM C 39. Average value of compressive strength came out to be $29 \mathrm{MPa}$ for column. The achieved concrete strengths of different batches of concrete as per tested concrete cylinders were quite close to desired value of strength. For desired strength of $28 \mathrm{MPa}, 29 \mathrm{MPa}$ was achieved.

\section{Casting Procedure}

Column specimen was casted in batch using wooden formwork. Concrete mixer was used for concrete making. Concrete mixture was poured in formwork and using electric vibrator its compaction was carried out. PVC pipe was used for hole formation and it was removed in some columns while in others it was let there even after concreting so that hole may retain its shape during testing and to avoid premature failure due to stress concentration and cracks formation near hole. A day later to casting; molds were removed and samples were cured for 28 days using wet hessian cloth.

\section{Test Setup and Testing Procedure}

After 28 days of curing of specimens, these were tested for axial compressive strength. This section discusses testing procedure of cast column, which is given in next paragraph.

Both ends of columns were encased in $51 \mathrm{~mm}$ high steel collars to prevent localized failure of columns. This arrangement also prevents buckling of column and resultant premature failure. But it was seen that some of the columns still failed due to crushing of concrete at the ends of columns.

For measurement of axial deformation, the linear variable differential transducer (LVDT) having maximum axial deformation capacity of $100 \mathrm{~mm}$ was used with P3 micrometer. For fixing LVDT, a hole was drilled at a distance of $195 \mathrm{~mm}$ from lower end of column and LVDT was mounted there. Another hole from $195 \mathrm{~mm}$ distance from upper end of column was also drilled for fixing angled steel plate. This assembly resulted in a distance of $610 \mathrm{~mm}$ between two holes that is axial deformation was noted for this column portion. This distance was later used for conversion of axial deformation to axial strain. P3 micrometer was operated from computer which was set for 1 second interval. Values so recorded were later converted to strain. The testing assembly mentioned in below given figure. 


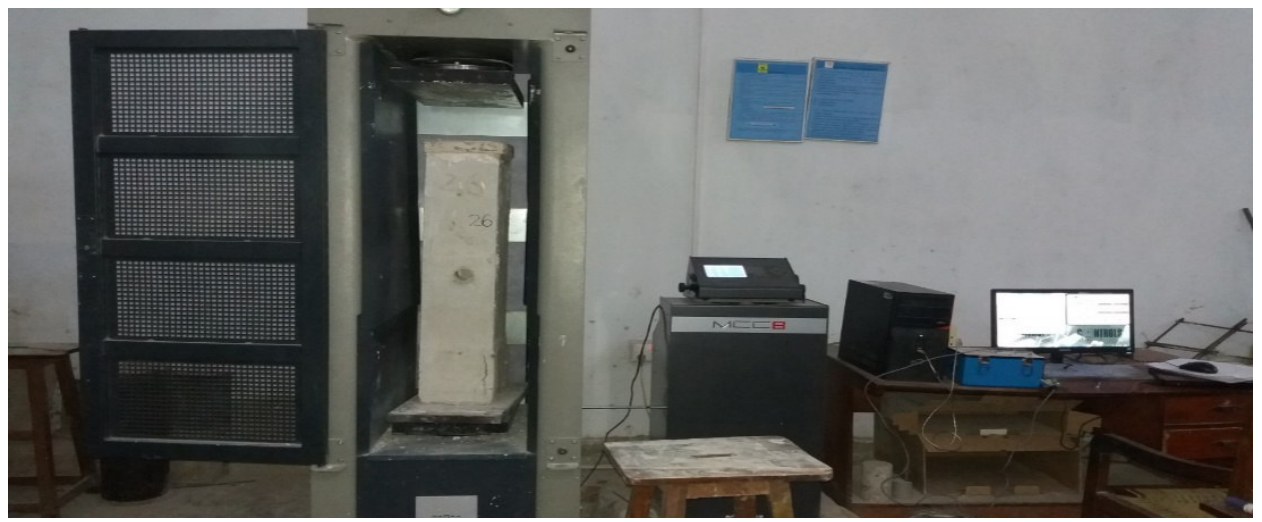

Testing Assembly, Fig\#01

\section{Failure modes}

In this section failure mode of tested RC column was discussed in detail. Columns' specimen was placed in compression testing machine and load was applied in $5 \mathrm{MPa}$ increments with a speed of $0.25 \mathrm{MPa} / \mathrm{sec}$. On increasing load, cracks started appearing at the ends of columns in some columns and near holes in others. Cracking led to spalling of concrete, thereby exposing steel rebars. Rebars started buckling on increasing load and after which the columns failed at its ultimate load in various failure modes which are described below.

Mainly the column failed due to formation of two intersecting diagonal cracks passing through holes. As the concrete has spalled off at this stage, therefore buckled rebars can be seen. In some columns single diagonal crack appeared at the mid length passing through the hole. While some of the columns failed due to localized buckling of rebars at the ends of columns. In columns with hole the cracking of hole was visible. The failed column has been shown in the figure given below.

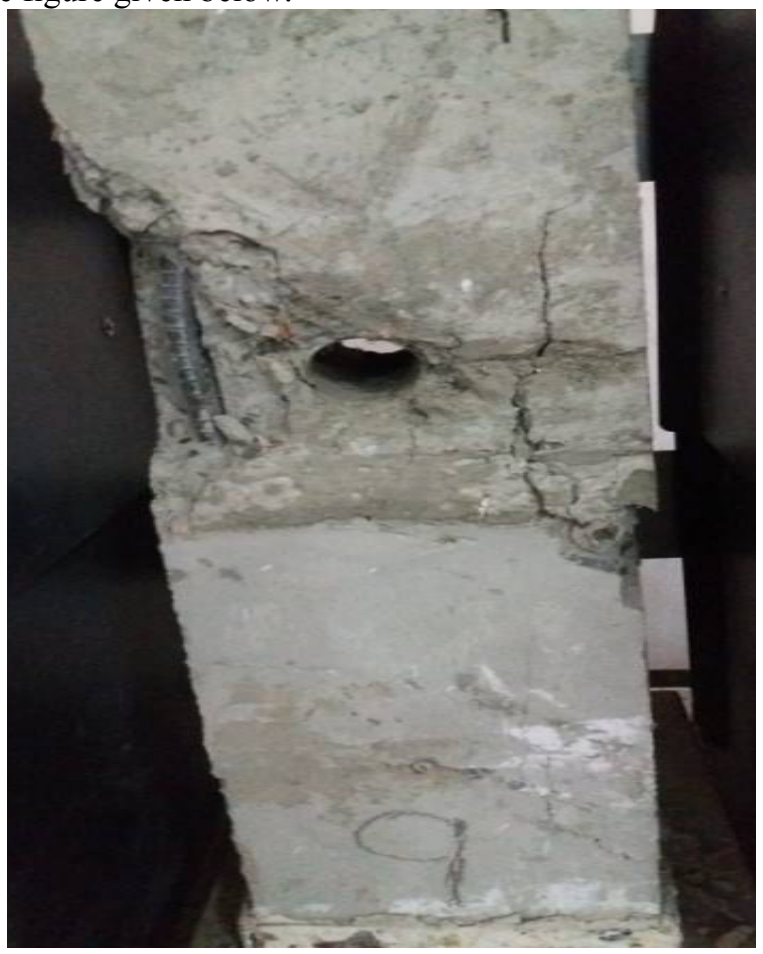

Failure mode of column, Fig \# 02.

The stress -strain relationship has been given in the following figure. 


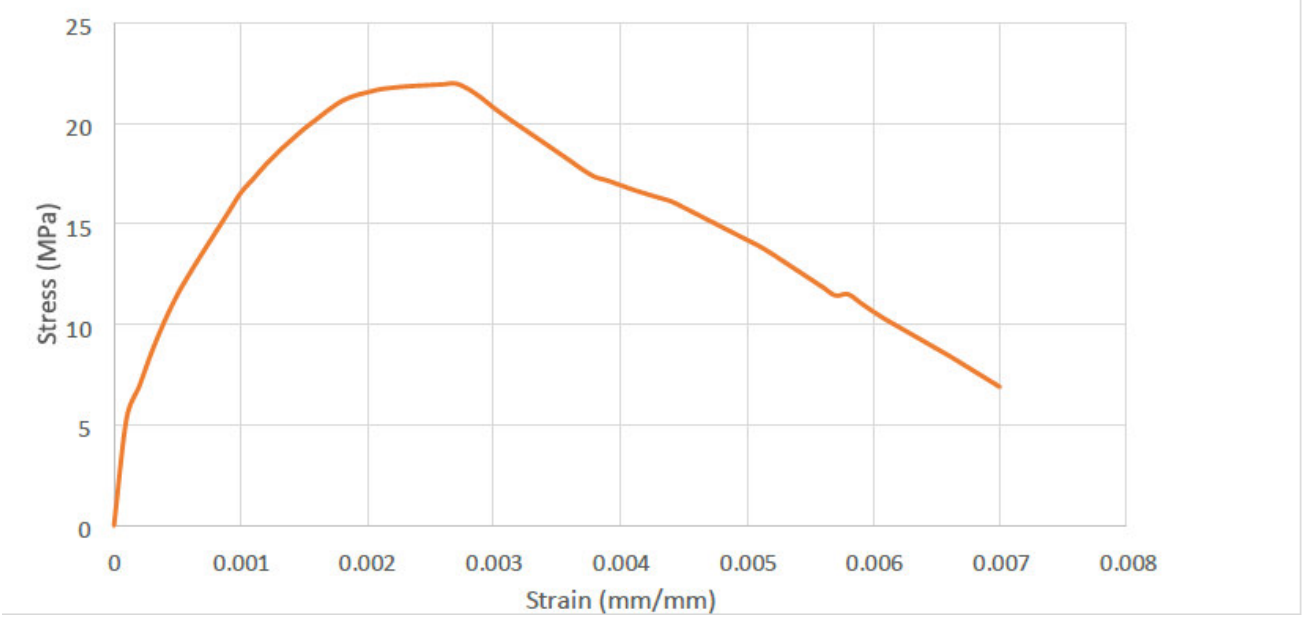

Experimental stress -strain relationship, fig \#03

\section{B).Numerical Simulation}

In order to investigate the influences of the hole on the RC Column a parametric finite element analysis has been undertaken using the finite element package ANSYS.The three-dimensional finite element model in finite element analysis, designed to verify the feasibility of finite element analysis, has the same sizes and material properties as the specimens in experimental method escribed before.

\section{Finite element model}

Reinforcement modeling. The three-dimensional 20-node element SOLID 186 is adopted to modelthe steel. Each node of the element has threetranslation degrees of freedom. This element is capable of capturing plasticity, large deflections, and large strains.

Concrete modeling. The three-dimensional 8-node element SOLID 65 is used to model the infilled concrete. Each node of the element has three translation degrees of freedom. This element is capable of capturing the effects of cracking in tension, crushing in compression, and plastic deformation.

Modeling of the concrete-steel interface. The contact elements TARGE 170 and CONTA 174 are employed to model the contact action between the steel members and the concrete. These contact elements allow the surfaces to separate but not penetrate each other. They combine as a contact pair through sharing a real constant. The coefficient of friction between the two faces is taken as 0:25 in the analysis.

Modeling of loading and boundary conditions. The same loading procedures and constraints as the experiments should be used in the finite element analysis. To simulate this action, the columns were held horizontally, the top and the bottom of column were fixed and the loads were applied on the free beam end. The loads were applied as static uniform load using displacement control at each node of the loaded surfaces, and the displacement increments are identical to the increments of the load.

\section{Numerical Results}

The following results were obtained through numerical simulation using ANSYS. 


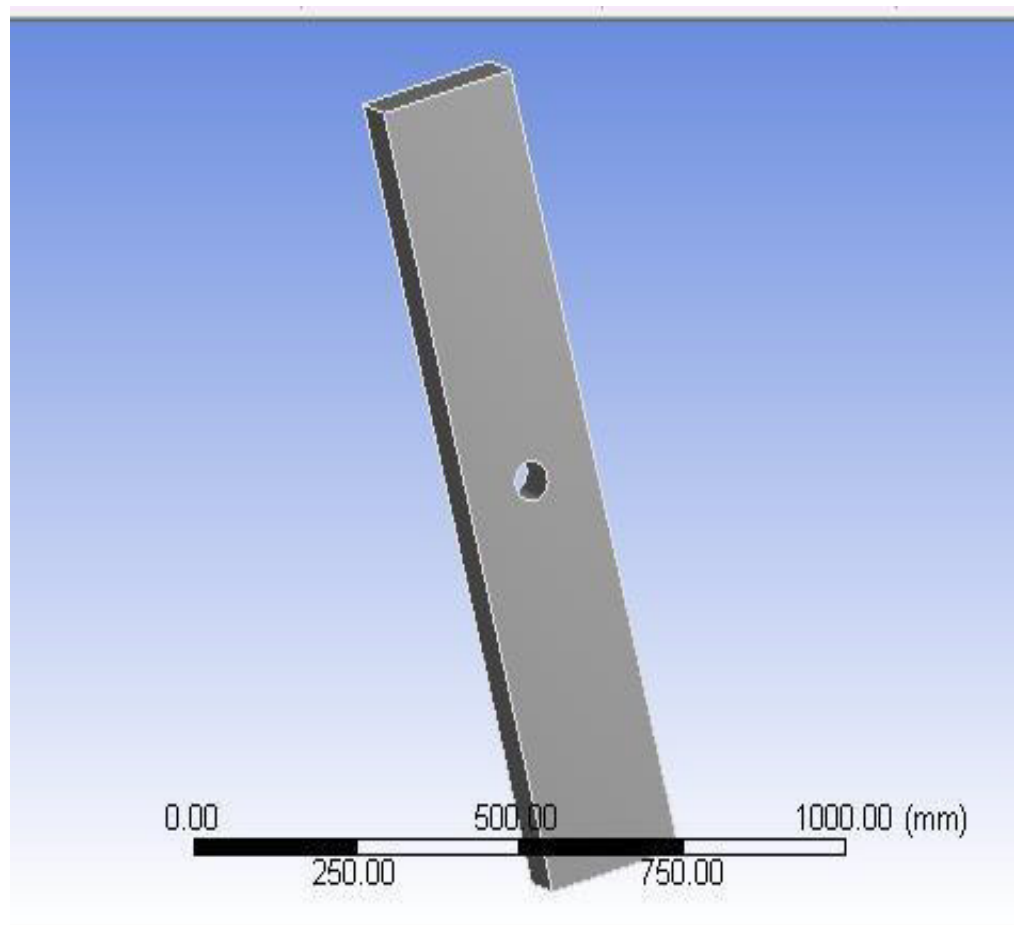

Model of column, fig \# 04

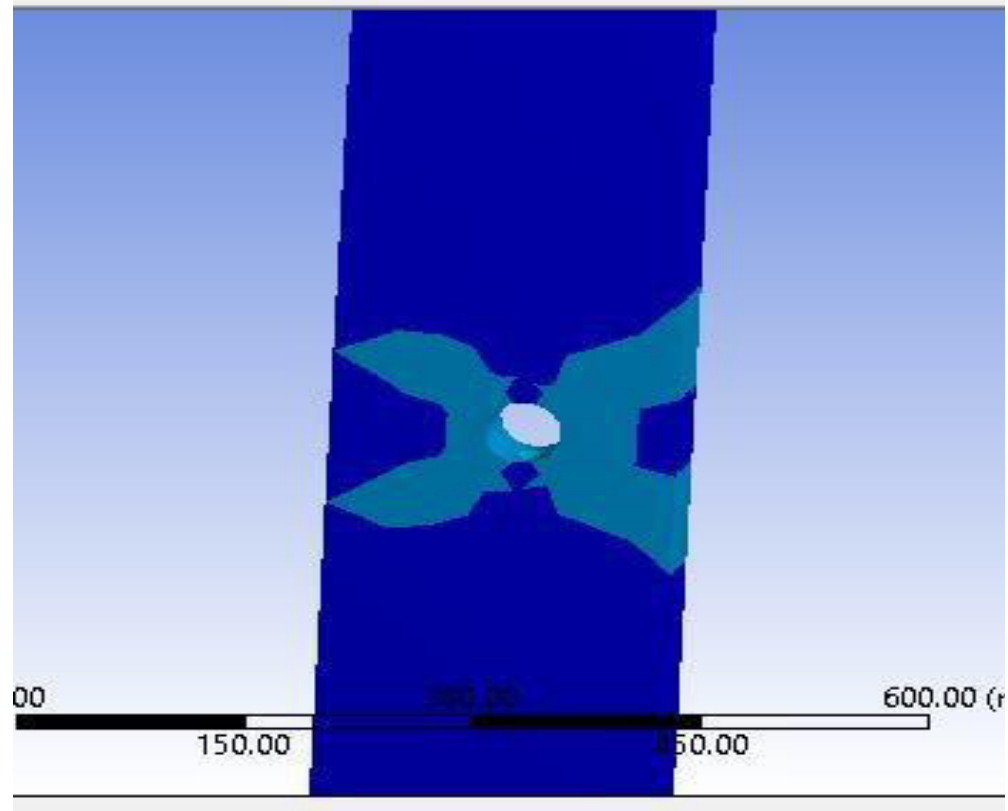

Cracked pattern of column around an opening,Fig \#05

The stress-strain relationship obtained using numerical simulation is given below. 


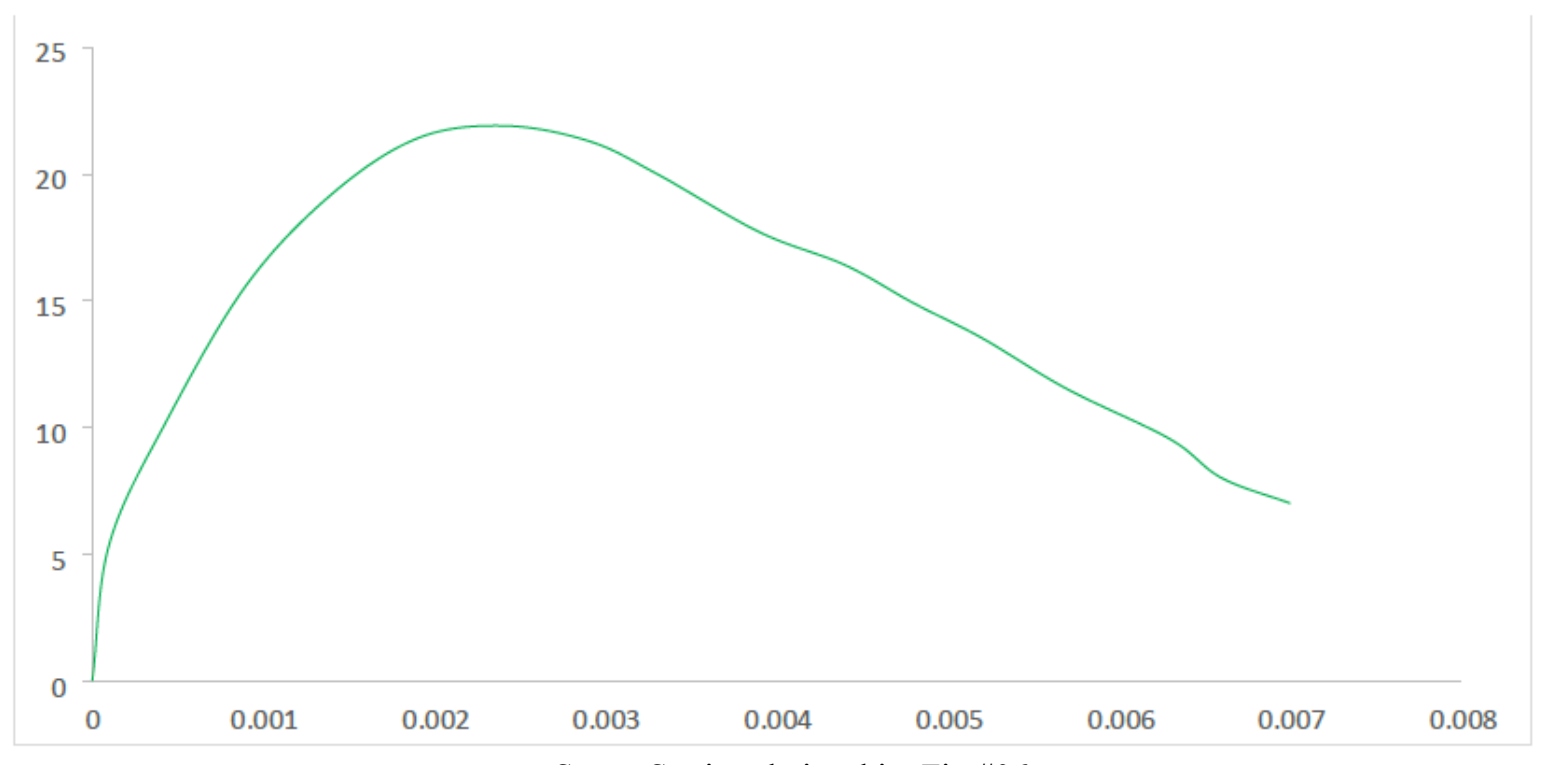

Stress-Strain relationship, Fig \#06

\section{Conclusion}

By considering all the facts and figures under the studied carried out in this project, we have concluded that the "finite element modelling" is the most reliable method developed so far for predicting pre-execution behavior of the structure under the real time situation. Also it is most easiest way to authenticate the research work by comparing it with the experimental results and thus a cost effective one too. The finite element modeling of the columns predict some minor deviation from experimental results, which might be due to the difference of material properties and climatic condition like temperature etc.

\section{Recommendations}

The behavior of the column around the hole was studied under the application of vertical loadings (gravity loads), Further investigation of the structure i.e. is column is required under the application of lateral load like winds and earthquake, so as to find out the stress-strain graph and behavior of column around the opening/hole.

\section{References}

[1].The finite element methods: Linear static and dynamic finite element analysis.T.J.R. Hughes. Dover Publications, 1987. Finite element procedures. K.J. Bathe. Prentice Hall, 1996.

[2].Abdel Rahman, H.H. and Hinton, E. (1986). "Nonlinear Finite Element Analysis of Reinforced Concrete Stiffened and Cellular Slabs". Computers \& Structures, Vol. 23, No. 3, pp. 333-350.

[3].Adeghe, L.N. and Collins, M.P. (1986). "A Finite Element Model for Studying Reinforced Concrete Detailing Problems". Publication No. 86-12, Department of Civil Engineering, University of Toronto.

[4].Arnesen, A., Sorensen, S. I. and Bergan, P.G. (1980). "Nonlinear Analysis of Reinforced Concrete". Computers \& Structures, Vol. 12, pp. 571-579.

[5]. ASCE Task Committee on Finite Element Analysis of Reinforced Concrete Structures. (1982). State-of-theArt Report on Finite Element Analysis of Reinforced Concrete, ASCE Special Publications.

[6]. Balakrishnan, S. and Murray, D.W. (1988). "Concrete Constitutive Model for NLFE Analysis of Structures".Journal of Structural Engineering, ASCE, Vol. 114, No. 7, pp. 1449-1466.

[7]. Barzegar, F. and Schnobrich, W.C. (1986). "Nonlinear Finite Element Analysis of Reinforced Concrete underShort Term Monotonic Loading". Civil Engineering Studies SRS No. 530, Univ. of Illinois at Urbana, Illinois.

[8].Basravi, Amirhossein. 2010. Finite element analysis of reinforced concrete column with longitudinal hole, Universiti Teknologi Malaysia, Faculty of Civil Engineering.

[9].Majeed, Hayder Qais. 2012. "Experimental and numerical study of the effects of creating openings in existing RC beams and strengthening with CFRP." Engineering and technical journal no. 30:2550-2561.

[10]. Ehab M. Lotfy (2013) "Nonlinear analysis of reinforced concrete columns with holes" ISSN

0976 - 4399 Faculty of Engineering, Ismaelia, Suez Canal University, Egypt. 